\title{
ISEA 2011. International Symposium on Electronic Art
}

MIKKEL THELLE*

Titel: ISEA 2011. International Symposium on Electronic Art.

Abstract: Rather than being a conference, ISEA 2011 is a festival of digital media, art and culture. The many different formats and activities are stimulating, but it is also sometimes difficult to find an overall perspective from which to describe the whole event. This year ISEA, which is one of the major digital festivals, was held in Istanbul, a city whose diversity was a mirror of the event itself. Among the many sessions can be highlighted themes such as "the logarithmic turning point", which focuses on the influence that digital programming has had on global culture; "media architecture", understood as interactive façades in urban spaces; "the curatorial gesture", about curating and archiving new media and the issues around the role of New Media Art in art history.

More generally, ISEA was permeated by the new media replication and unpredictability of new media, one expression of which was the festival's "Uncontainable" curatorial theme. As a negotiation of form and content, museums of cultural history in particular have something to learn from art and new media.

Key words: New Media Art, digital media, conference, media culture, curating, urban space.

ISEA SOM GLOBAL OG MANGFOLDIG FESTIVAL

International Symposium of Electronic Arts er en konference om digital kunst og design, men med en bredere samfundsmæssig horisont. ISEA er en sammensat skare af kunstnere, kulturinstitutioner, kuratorer, designforskere og softwareprogrammører fra hele kloden, omend med en mest vestlig og mellemøstlig tyngde. Og der var efter sigende over to tusinde deltagere. Dermed bliver ISEA en af de store, europæiske begivenheder for digital kultur på linje med Ars Electronica eller Documenta.

Med denne sammenligning bliver det også forkert at kalde ISEA en konference. Med sin bredde og sammensætning af formater er det snarere en festival, der fejrer den voksende måske vildtvoksende - mangfoldighed i feltet omkring digitale medier, kultur og kunst. Således kunne deltagerne vælge mellem sideløbende paper sessions, udstillinger, workshops og forskellige digitale events. Et samarbejde 
med biennalen i Istanbul gav en yderligere dimension til mangfoldigheden.

Med denne fulgte også forvirringen. Scenen var sat i Istanbul, og de primære aktiviteter foregik i Sabanci Center, et afsnit af byens universitetskompleks, der ligger tyve minutters kørsel uden for centrum. Samtidig foregik en lang række begivenheder på og omkring den centrale Taksim-plads, hvorfor der sjældent var et egentligt plenum til stede ved keynotes osv. To sikkerhedskontroller på vej ind $\mathrm{i}$ Sabanci center gav også en fornemmelse af mindre cirkulation.

Symposiet var ikke tematiseret som sådan, men der var lagt et kuratorisk tema, "Uncontainable", der var ledende for de fleste udstillinger og events. Idéen var at understrege nye mediers tendens til at glide som sand mellem fingrene i forsøg på definition og afgrænsning. Det lykkedes.

Jeg er her på konferencen for at diskutere og præsentere en idé til et muligt digitalt samarbejde omkring by og mobilteknologi. Den lille gruppe jeg tilhører, glider ind og ud mellem sessions og udstillinger, sejler over Bosporusstrædet til udstillinger af logaritmisk kunst, skilles, samles og diskuterer. Istanbul er en konstant vibrerende og pulserende ramme om oplevelserne.

\section{FRA LOGARISME TIL LOGARITME}

Første nedslag er en keynote fra William Uricchio, professor i litteratur og Comparative Media ved MIT med titlen "The Logarithmic Turn”. Uricchios grundlæggende påstand er, at logaritmen som fænomen er grundlæggende for det, der kommer efter den industrialiserede modernitet - hvad vi så end skal kalde det.

Logarismen - bemærk forskellen - som er beregningen med et bestemt, rationelt facit, har domineret den moderne periode, sagde Uricchio. Hele moderniteten og industrialismen var præget at denne beregningskultur. Men efter 2. Verdenskrig kom den digitale proceskraft, der gav logaritmen - nu med $\mathrm{t}-$ momentum. Ideen om at skabe en kode og lade den konstruere uforudsete mønstre skabte en ny kunst og et nyt forhold mellem subjekt og objekt. Skridtet fra udregning til programmering introducerede det uforudsete i den digitale verden, inspirerede postmoderne teori og æstetik og var central for udviklingen af kaosteorien.

Uricchio kom med mængder af mere eller mindre motiverede eksempler på denne forandring af verden - taggingkultur, multiple identiteter og tekst som økosystem - og det var inspirerende at høre på. Men det var også tydeligt, at han kom fra en baggrund i litteratur-og mediestudier, og at både den historiske og teknologiske analyse kunne have været lidt mere dybdegående.

\section{MEDIEARKITEKTUR}

En session d.19.9. havde den uigennemskuelige titel "The Media Space. Evolving Media Architecture and its Legend". Her handlede det om mediearkitektur, d.v.s. hvordan man meningsfuldt sammentænker bygninger og mediering. Designer Christoph Kronhagel præsenterede Media Facades, et produkt hvor man projicerer billeder på bygninger beklædt med reflekterende lameller, som er usynlige indefra. Han var tydeligvis på salgsturné, men det interaktive potentiale i idéen er stor, for så vidt man kan gøre "mediehuden" interaktiv. Han fortalte da også om et projekt hvor et tysk byråd overvejede en "deltagervæg", hvor høringsprojekter og anden borgerinddragelse kunne faciliteres af et sådant medie-landmark. 
164 I dansk museumssammenhæng kan man enten anlægge den synsvinkel at alle de flotte, museale bygninger, vi har, ikke skal voldtages af kæmpe powerpointinstallationer. Men man kan også sige, at der her åbnes for at gentænke forholdet mellem by og kulturinstitution og mellem sted og rum i faktiske rumlige eksperimenter, eksempelvis kunne man tænke sig bygningsfacaden som en API (Application Programming Interface - en grænseflade for flere programmer og datastrømme), hvor indholdet af samlinger og viden indenfor kanaliseres direkte ud i det omgivende rum, responderende på brugeres aktivitet inde og ude.

Arkitekt Eckehardt Loiholdt havde en mere rumlig approach og inddragede bygningsfacadens historie i en overvejelse om, hvordan man kan "vende indersiden udad" på en bygning. Forskellige teknikker og teknologier blev nævnt, men det interessante var den funktionelle overvejelse $\mathrm{i}$ at kommunikere bygningens intention og brug gennem transparente og oplyste facader.

Endelig blev problematikken omkring forbindelse mellem det indre og det ydre taget op af en repræsentant for Ars Electronica Future Lab. De havde for et større tysk firma etableret en digital "vej", der førte besøgende ind i en bygning og til et særligt galleri. Vejen bestod af en oplyst, 200 meter lang skærm, hvor animerede vanddyr fulgte efter den besøgende. Vanddyrene var tilsyneladende forbundet til den forretningsaktivitet der foregik i huset altså en kunstnerisk repræsentation spundet ind $\mathrm{i}$ en markedsføringsinstallation. Meget fikst, omend min kunstnerledsager ikke var imponeret over det kunstneriske indhold.

Idéen om det intelligente byrum blev i denne session meget mere konkret og forskellige principielle spørgsmål materialiserede sig: Hvordan kan sådanne strukturer undgå at do- minere byrummet fuldstændig? - som i et nyt Blade Runner, der vist allerede er virkelighed $\mathrm{i}$ nogle asiatiske megabyers centre. Hvad er eksistensberettigelse og succeskriterium for en sådan type kommunikation i byrummet? $\mathrm{Og}$ ikke mindre vigtigt - hvordan etableres hensigtsmæssige partnerskaber til en eventuel finansiering af de bekostelige strukturer?

\section{KURATERING}

En session om kuratering og arkivering i nye medier tiltrak logisk undertegnede. Kurator Karen Gaskill udredte, hvordan kuratorens rolle har udviklet sig fra den oprindelige betydning af ordet (caretaker) til i 1960'erne at skifte betydning i og med at den kuratoriske praksis spaltes ud i mange retninger. Det, Gaskill kalder "den kuratoriske gestus" kommer frem, dvs. at selve sammensætningen af en udstilling, valget af rum og interaktionsformer bliver et værk i sig selv. Kuratering går hen og bliver " the most radical form of cultural practice today", intet mindre. Kuratoren arbejder mellem den private kunstproduktion og den offentlige konsumption af kunst, og bevæger sig dermed i et magtfuldt felt, hvor selve det at udstille bliver en selvstændig diskurs, som får mere og mere medieopmærksomhed. Gaskill kobler denne udvikling med de nye medier, der bryder grænserne for den tidligere forståelse af kunst ved at være interaktiv, ikke-lineær og sammensat af sociale, visuelle og materielle elementer. En kommentar hertil kunne være at med introduktionen af en mere åben æstetik netop i 1960'erne skifter den kuratoriske praksis over en bred kam og ikke kun i forbindelse med digitale medier - men som kulturhistoriker skal man nok blive ved sin læst i denne sammenhæng.

Kurator og kunsthistoriker Christiane Paul 
fra New York udlagde en definition af kunst i nye medier - min oversættelse af New Media Art - som noget der er processuelt, netværksbaseret, interaktivt, ikke-lineært og modulært - og som ved alle disse kendetegn adskilte sig fra den traditionelle kunst. Siden sin fremkomst har New Media Art således også være holdt på et sidespor i forhold til den anerkendte kunst. Dette synspunkt deltes af Anett Dekker, kurator og kunstner fra Holland. Ifølge hendes research var det mindre end 1 procent af de store kunstmuseers samlinger, der indeholdt nye medier.

\section{ARKIVERING}

Diskussionen om arkivering tog udgangspunkt i, at det af tekniske grunde kan være uoverskueligt at gemme mange typer af digitalt medieret kunst. For eksempel mente flere oplægsholdere, at bare det at bevare det hardware, der skulle til for at mediere værkerne, ville kræve et mindre teknisk museum. Til det kan man sige, at arkiveringsdiskussionen for kunstværker såvel som for digitale medier og genstande på kulturhistoriske museer også handler om definition. Kort sagt: er det en materiel samling af objekter, vi skal gemme, eller er det en begivenhed? I første tilfælde er hele bevaringsproblematikken som nævnt kompliceret. I det andet tilfælde er det i stedet en dokumentation af selve begivenheden eller situationen, der skal gemmes. I fluxus-kunsten var det en pointe, at begivenheden netop ikke skulle kunne indfanges eller gentages. Dilemmaet gælder i høj grad for vores forhold til de digitale medieformer, som vil tilflyde samlingerne i stigende grad fremover, og det giver ikke sig selv, om der er tale om materielle genstande eller begivenheder. Det er et valg der må træffes.
KURATORERNES NYE ROLLE SOM MEDFOR-

$\mathrm{Nu}$ handlede dette om kunst og nye medier i forhold til kunstværkets og kuratorens status men man kan generalisere diskussionen. Med brugen af nye medier i såvel formidling som indsamling og forskning får museerne og museumsinspektørerne over en bred kam en anden rolle at spille end tidligere - som medfortæller, designer og kommunikator. Måske er det kunstmuseerne der i højeste grad har mærket denne udvikling, men på et eller andet tidspunkt kommer alle museumsfolk til at forholde sig til det.

Et andet forhold, man kan trække frem fra denne diskussion var et begreb, der gik igen mere eller mindre implicit på flere planer i ISEA 2011, nemlig det participative perspektiv, eller på almindeligt dansk, deltagelse. Med logaritmen, installationskunsten og sammenstillingen af forskellige medier blev kunstneren som skabende individ et skrøbeligt begreb. Det bliver tematiseret i 1960'erne i flere kulturelle praksisser, bl.a. af Roland Barthes om forfatterens rolle. Med denne skrøbelighed åbnes for en bred forståelse af kollektivt forfatterskab, der gik igen som koncept i flere keynotes på symposiet.

Denne udvikling er central for forståelsen af den rolle, sociale medier spiller i dag, og som vi formentlig bør holde fast i og udvikle, nemlig at museets stemme og rolle i det digitale landskab må finde sig til rette blandt mange andre kompetente stemmer og roller. Konstateringen kan lyde banal, men får sandsynligvis store konsekvenser for vores identitet og autoritet $\mathrm{i}$ fremtiden. Vi er som kulturinstitutioner del af et kollektivt forfatterskab til fortællingen om kulturarven.

Det var rimeligt klart, at det kollektive for- 
166 fatterskab kommer fra kunsten, og at de digitale medier har forstærket denne tendens. Det hænger også sammen med et andet forhold, som man kunne høre igen og igen på ISEA: replikation, kopiering, gentagelse som del af det digitale univers er allestedsnærværende, og bliver i høj grad betragtet som en frigørelse, idet alle kan tilegne sig det digitale, bearbejde det og videregive det. Kunsten bliver at sammensætte og behandle allerede skabte værker, referere og henvise i en uendelig produktion af tegn, en uendelig semiosis, som Umberto Eco ville formulere det.

\section{BRUGERINDDRAGENDE PROCESSER I FREMTIDIG BYUDVIKLING}

Selv deltog undertegnede i en workshop om deltagelse og byrum. Brugerinddragende processer $\mathrm{i}$ forbindelse med byudvikling og planlægning er et voksende felt i disse år, og diskussionen byggedes op i en række indlæg om mobilteknologi, design, og principielle overvejelser til understøttelse af dette. Kan man gennem en kombination af sociale medier, mobile apps og aktive overflader skabe et digital "ydre" rum for kollaborativ udvikling, såkaldt "co-creation"? Og kan en kombination af "indre" spilmekanismer, 3D-animation og multitouchgrænseflader give mulighed for kvalificeret interaktion, valg og forslag til nye byrum? Et centralt problem var at skabe en platform for kvalifikation af deltagelse. Mange tilgange til deltagelse har det kvantitative succeskriterium - jo flere, jo bedre. Hvis folk føler sig hørt er det et mål i sig selv, og derfor er mange godt, jo flere jo bedre. Men det giver ikke nødvendigvis gode forslag, endsige artikulationer af reelle behov, drømme og ønsker. Fra den kulturhistoriske side kunne man sige, at tilgængelighed til kilder og historier om by- ens fortid kan kvalificere en holdning til dens fremtid. Byen er en proces i konstant udvikling og indvikling, og et bagudrettet blik på elementernes tilblivelse kan give basis for at vælge hvilke af dem, der har værdi på et socialt, æstetisk eller rumligt plan. Design af processerne over tid blev også fremhævet: Det tyndslidte begreb "ejerskab" er en kompliceret størrelse, og en af omdrejningspunkterne her er måske en gennemsigtig arkitektur i beslutningerne - ved at give forslag, som kunne videreudvikles af andre for så at konkurrere med hinanden og komme til et næste niveau, hvor eksperter trådte ind, kvalificerede og gav resultatet tilbage til konkurrencen i en iterativ fremdrift, var en løs idé, der kom ud af diskussionerne. Inspirerede forlod forsamlingen det lille lokale under Sabanci-centrets spektakulære tårne.

\section{INDHOLD OG FORM}

Uncontainable kan både betyde "udefinerbar", men også "ubeskeden”. Og ISEA var alt i alt en oplevelse af uanede og vildtvoksende muligheder for de digitale medier. Der var en lang række sidestillede sessioner og workshops, og en kritisk gennemgang af programmet giver et indtryk af "kongres-syndromet", at alle fortolkninger af temaet er taget ind; der var robotworkshops, events med animerede bakteriestrukturer og en hjemmelavet satellit ved siden af forelæsninger over, hvordan kollaborative metoder påvirker kreative designprocesser. Det udelukkede dog hverken kvalitet eller udsyn i de møder, der foregik rundt omkring i kælderlokalerne.

ISEA drejer sig om digitale medier og kunst. Men diskussionerne og problemerne kan i høj grad ses som principielle for alle typer kulturinstitutioner. Der er dog en forskel, 
som må ses mere grundlæggende, nemlig spørgsmålet om form og indhold. I kunstverdenen og store dele af den senmoderne kulturteori er der sat spørgsmålstegn ved adskillelsen af disse to begreber, men hvis man ser på museerne som institutioner, træder de $\mathrm{i} \varnothing j n e n e$ igen. Det kulturhistoriske museum vil oftest betragte digitale medier som en ramme om et indhold, især i forbindelse med formidling. Når kunstværker formidles, er der ofte en nærmere forbindelse mellem de to, og selve formen kan til tider være det kunstneriske indhold. Det er muligvis derfor, at den digitale forandring har slået så meget igennem på kunstmuseerne. Muligvis er det derfor, andre typer af museer kan lære noget af disse.

Gennem gallerier, på både og i auditorier blev de digitale potentialer udforsket, udstillet og udvidet. Overvågningsteknologi som kunst, logaritmiske blomster udfoldede på skærme og assemblager af medier hang som dirrende erindring i sanserne ved afrejsen fra Istanbul.

*Mikkel Thelle, museumsinspektør $p a ̊$

Nationalmuseet, København, Danmark

Adresse: Mikkel Thelle,

Islands Brygge 15,1tv, $2300 \mathrm{~S}$

E-mail:mikkel.thelle@natmus.dk 